\title{
Digitalisasi Data Perpustakaan Dalam Proses Peminjaman dan Pengembalian Buku pada Perpustakaan Sekolah Islam 'Uluwwul Himmah Medan.
}

\author{
Purwadi $^{1}$, Widiarti Rista Maya ${ }^{2}$, Saniman $^{3}$,Elfitriani ${ }^{4}$, Suardi Yakub \\ 1.5 Program Studi Sistem Informasi Stmik Triguna Dharma \\ ${ }^{2}$ Program Studi Teknik Komputer Stmik Triguna Dharma \\ ${ }^{3}$ Program Studi Sistem Komputer Stmik Triguna Dharma \\ ${ }^{4}$ Program Studi Manajemen Informatika Stimik Triguna Dharma
}

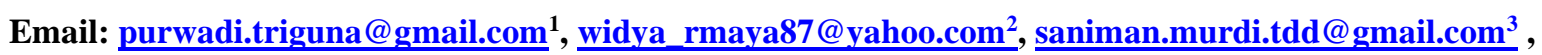
elfitriani@trigunadharma.ac.id ${ }^{4}$, yakub_suardi@trigunadharma.ac.id ${ }^{5}$

\begin{abstract}
Abstrak
Sekolah 'Uluwwul Himmah Medan adalah Salah satu sekolah dan taman Kanak-kanak yang ada di kota Medan dimana salah satu penunjang kegiatan belajar mengajar adalah perpustakaan sekolah sebagai media pengembangan ilmu bagi anak-anak di Sekolah tersebut.Pada 'Uluwwul Himmah Medan Pengelolaan perpustakaan sekolah masih dilakukan secara manual, untuk itu dibutuhkan system terkomputerisasi dalam mengelola buku perpustakaan baik proses peminjaman dan pengembalian buku.Dengan adanya system yang telah dibangun maka proses pengelolaan buku perpustakaan baik proses peminjaman dan pengembalian dapat dilakukan secara cepat dan tepat.
\end{abstract}

Kata kunci: Sekolah 'uluwwul himmah, proses pengembalian dan peminjaman buku, perpustakaan

\begin{abstract}
'Uluwwul Himmah Medan School is one of the schools and kindergartens in Medan where one of the supporting teaching and learning activities is the school library as a medium of science development for children in the school. At 'Uluwwul Himmah Medan School library management is still done manually, for that it takes a computerized system in managing library books both the process of borrowing and returning books. With the system that has been built, the process of managing library books both the process of borrowing and returning can be done quickly and appropriately.
\end{abstract}

Keywords: 'Uluwwul Himmah School, The process of returning and borrowing books, Libraries

\section{PENDAHULUAN}

Sekolah Uluwwul Himmah Medan merupakan sebuah lembaga pendidikan Islam yang menyelenggarakan pendidikan untuk setingkat Paud (Taman Kanak-kanak), SD dan SMP namun lebih memfokuskan kurikulum pendidikannya dibidang pendidikan agama Islam.Berdasarkan Undangundang Repulik Indonseia No. 20 Tahun 2003 tentang sistem pendidikan nasional dinyatakan bahwa, Pendidikan adalah usaha sadar dan terencana untuk mewujudkan suasana belajardan proses pembelajaran agar peserta didik secara aktif mengembangkan potensidirinya untuk memiliki kekuatan spiritual keagamaan, pengendalian diri, kepribadian,kecerdasan, akhlak mulia, serta keterampilan yang diperlukan dirinya, masyarakat, bangsa dan negara(Nasional, 1982).Pendidikan dianggap mulai berkembang pada masa orde baru, sehingga dapat dikatakan masa tersebut sebagai era pembangunan nasional karena didukung oleh instruksi presiden (Inpres) namun pengaplikasiannya hanya terjadi dari segi kuantitas tanpa diimbangi dengan pengembangan dari segi kualitas(W \& Desi, 1997).Oleh karena itu pengembangan sekolah dalam hal kuantitas dan kualitas harus seimbang.

Sejak awal berdirinya lembaga pendidikan Uluwwul Himmah ini hingga sekarang telah mendapat respon yang positif ditengah masyarakat, yang ditandai dengan semakin bertambahnya 
jumlah siswa dan meningkatnya antusias orang tua untuk menyekolahkan anak-anaknya di lembaga ini, sehingga pihak sekolah harus membatasi jumlah penerimaan siswa yang masuk, akibat terkendala masalah sarana dan prasarana serta tenaga pendidik. Untuk itu pihak sekolah berencana untuk melakukan peningkatan terkait permasalahan tersebut.

Pada Sekolah Uluwwul Himmah Medan salah satu fasilitas yang dimiliki adalah perpustakaan. perpustakaan adalah sebuah koleksi buku dan majalah. Walaupun dapat diartikan sebagai koleksi pribadi perseorangan, namun perpustakaan lebih umum dikenal sebagai sebuah koleksi besar yang dibiayai dan dioperasikan oleh sebuah kota atau institusi atau sekolah, serta dimanfaatkan oleh masyarakat atau siswa-siswi yang rata-rata tidak mampu membeli sekian banyak buku dengan biaya sendiri.Sedangkan perpustakaan digital adalah bentuk perpustakaan yang keseluruhan koleksinya memakai format digital yang disusun dalam sebuah arsitektur komputerisasi. Arsitektur ini disusun dalam sebuah proyek yaitu proyek perpustakaan digital.

Pada Sekolah Uluwwul Himmah medan system pengolahan peminjaman dan pengembalian masih dilakukan secara manual.Dari permasalahan tersebut, Untuk memudahkan pegawai sekolah dalam proses mengelola peminjaman buku dan pengembalian buku ,maka dibutuhkan berupa aplikasi terkomputerisasi yaitu aplikasi perpustakaan.maka dari itu kami dari team pengabdian STMIK TRIGUNA DHARMA, melakukan pengabdian dengan mengangkat judul "Digitalisasi Data Perpustakaan Dalam Proses Peminjaman dan Pengembalian Buku pada Perpustakaan Sekolah Islam 'Uluwwul Himmah Medan.Diharapkan dengan dilakukan pengabdian ini, dapat bermanfaat bagi pihak sekolah dan dapat diaplikasikan dalam mengelola perpustakaan yang ada di Sekolah 'Uluwwul Himmah Medan.

\section{METODE PELAKSANAAN}

Kegiatan Pengabdian kepada masyarakat ini dilaksanakan di satu lokasi sekolah, yaitu lokasi yang sedang digunakan untuk kegiatan belajar mengajar yang ada di 'Uluwwul Himmah Medan. Adapun metode yang digunakan dalam pelaksanaan kegiatan pengabdian kepada masyarakat ini adalah melalui 3 fase, yaitu :

1. Fase Pra Kegiatan,meliputi:
a. Pendekatan,
b. Perencanaan
c. Perancangan skenario.

2. Fase Pelaksanaan Kegiatan, meliputi:
a. Pengarahan,
b. Implementasi Program dan pengujian sistem
c. Dokumentasi.

3. Fase Pasca Kegiatan, meliputi:
a. Evaluasi
b. Produksi
c. Sharing

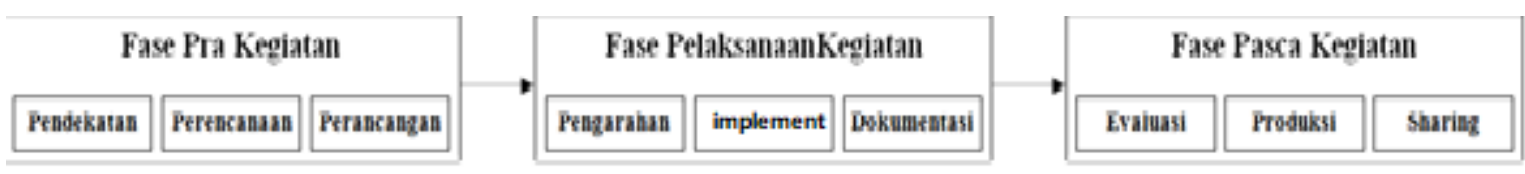

Gambar 1. Fase kegiatan pengabdian masyarakat.

\section{HASIL DAN PEMBAHASAN}

Beranjak dari kebutuhan pihak sekolah untuk membantu dalam pengelolaan data perpustakaan secara digitalisasi maka dilaksanakanlah kegiatan pengabdian kepada masyarakat ini sebagai salah satu solusi yang diberikan dalam bentuk pembuatan aplikasi perpustakaan dalam proses peminjaman dan pengembalian buku serta laporan data perpustakaan. Dalam fase Pelaksanaan Kegiatan, dimana tahapan yang dilakukan adalah pengarahan, yaitu mengarahkan para peserta yang bertindak sebagai aktor untuk memposisikan diri agar melakukan aktifitas sesuai skenario yang telah direncanakan sebelumnya. 


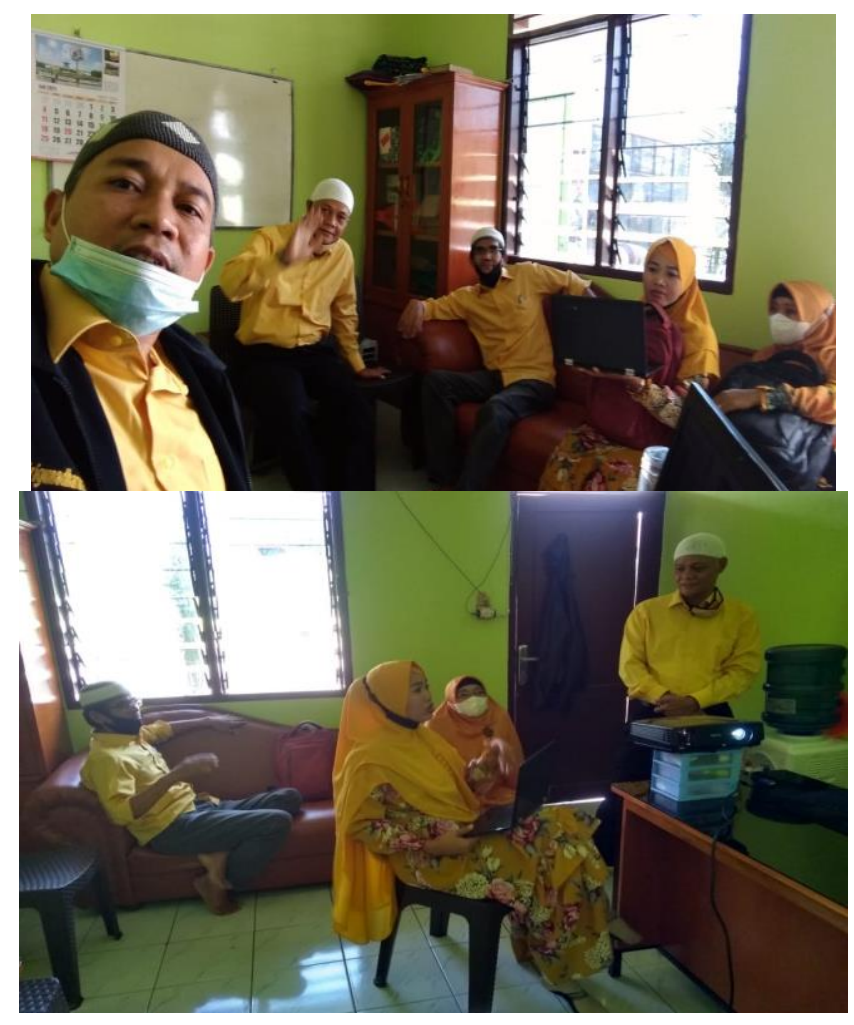

Gambar 2. Fase pelaksanaan kegiatan pada tahap pengarahan

Selanjutnya kegiatan yang dilakukan adalah Implementasi program yang dilakukan ke pihak sekolah untuk mengetahui cara penggunaan program aplikasi dan untuk mengetahui kebutuhankebutahan ataupun kekurangan program agar bisa digunakan pada sekolah 'Uluwwul Himmah.

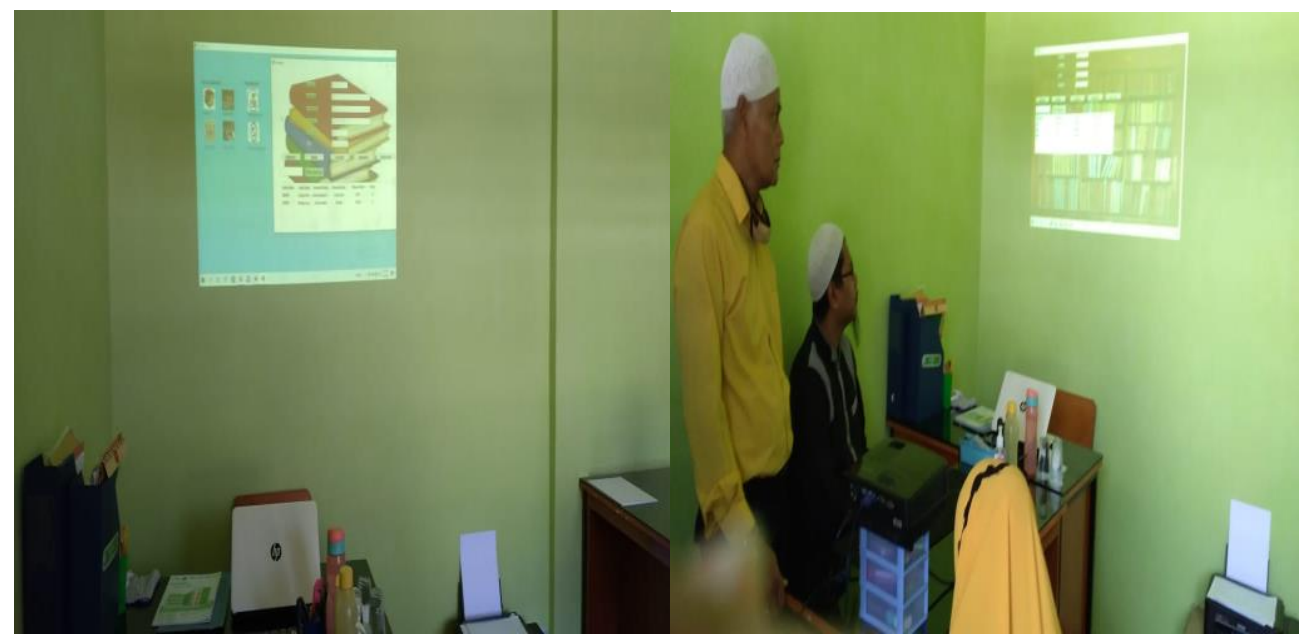

Gambar 3. Kegiatan Implementasi Program

Disela-sela kegiatan implementasi program telah berakhir, dilakukan pendokumentasian yang bertujuan untuk pembuatan laporan serta sebagai bukti pendukung untuk luaran pelaksanan kegiatan pengabdian masyarkat. 


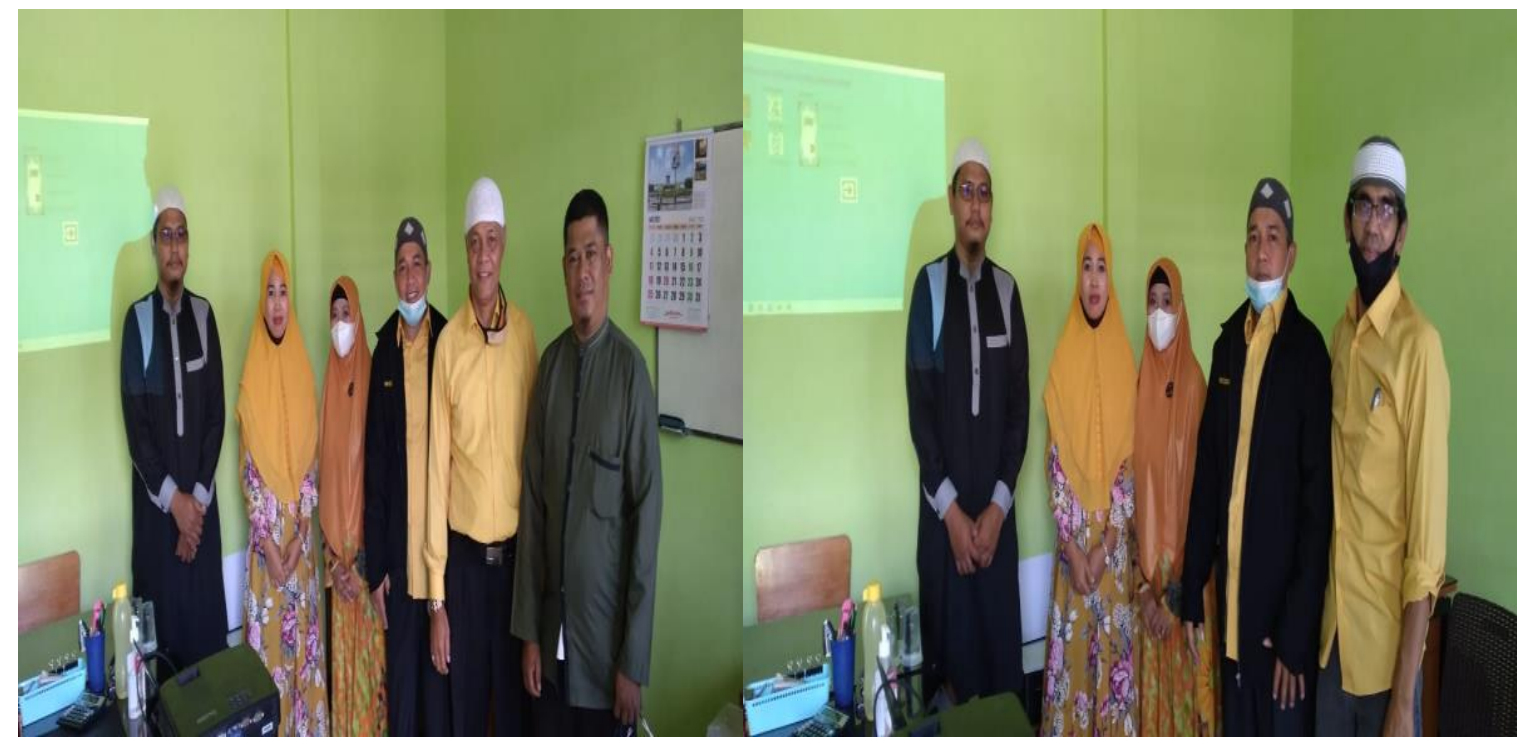

Gambar 4. Kegiatan dokumentasi dalam tahap pelaksanaan kegiatan

Setelah fase kedua (fase pelaksanaan kegiatan) selesai, maka fase ketiga yaitu pasca kegiatan dilakukan dalam tiga tahapan, yaitu evaluasi, produksi dan sharing. Dalam tahapan evaluasi, kegiatan yang dilakukan berupa pengujian program sejauh mana program aplikasi tersebut berjalan secara maksimal, Editing (pengeditan) Program aplikasi dan Crosscek hasil sementara dengan pihak sekolah untuk mendapatkan betuk visualisasi program yang sesuai dengan harapan pihak sekolah untuk dapat digunakan.

Pada kegiatan pengeditan data aplikasi yang digunakan adalah Visual Basic 2008 dan laporan data untuk perpustakaan digunakan yaitu Cristal report.Adapun gambarnya dapat dilihat sebagai berikut :

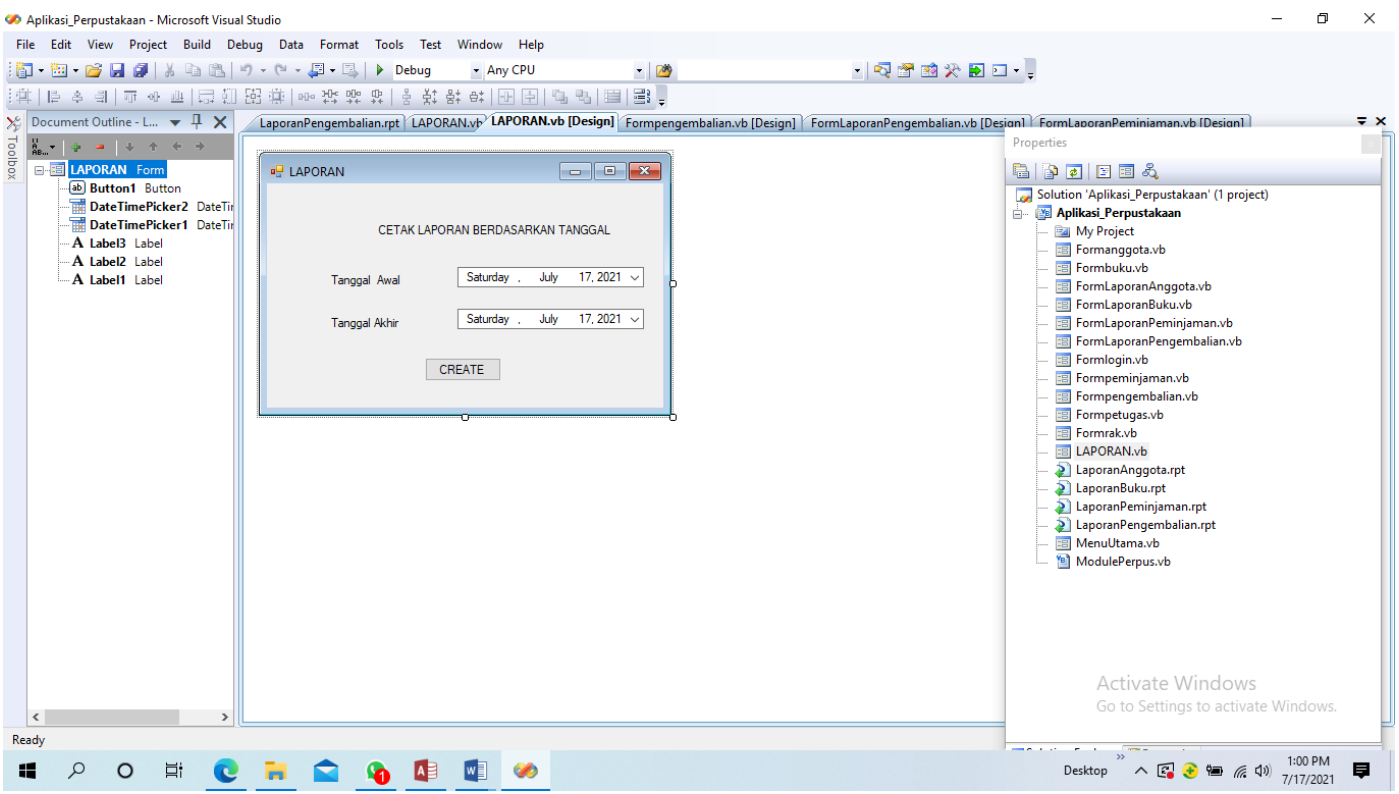

Gambar 5. Kegiatan pengeditan pada fase pasca kegiatan menggunakan aplikasi visual basic 2008

Selain itu juga digunakan aplikasi pendukung berupa Cristal Report, Untuk membuat laporan. Pada fase implementasi program adapun kekurangan yaitu penambahan dalam membuat laporan berdasarkan parameter tanggal yang dapat dilihat pada gambar 5, yaitu kegiatan pengeditan baik menggunakan visual basic maupun cristal report. 


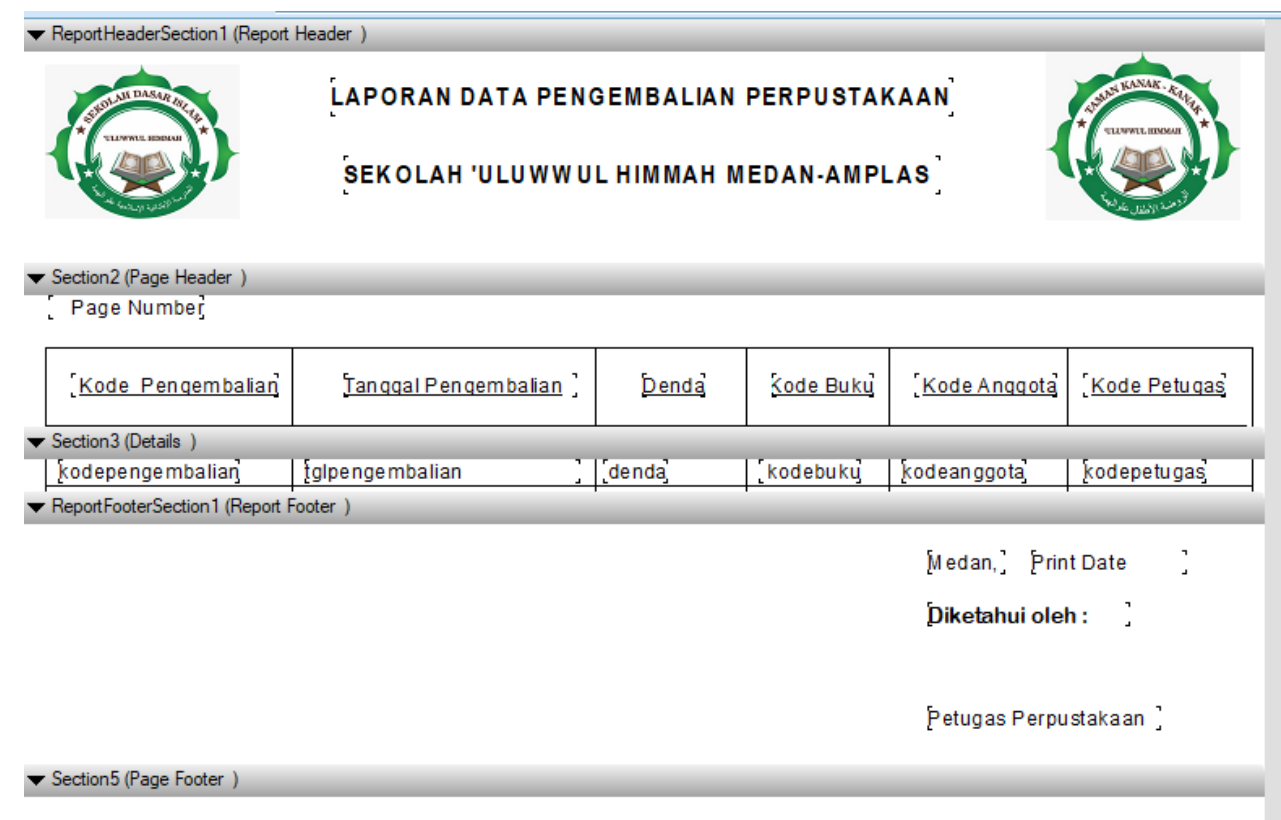

Gambar 6. Aplikasi Cristal report dalam membuat laporan buku perpustakaan

Setelah proses editing atau penyempurnaan program aplikasi perpustakaan sudah selesai tahap selanjutnya yaitu membuat file tersebut dalam bentuk winzip dan menyimpan nya kedalam bentuk DVD, untuk dapat diserahkan ke pihak sekolah agar dapat digunakan oleh pegawai perpustakaan dalam mengelola buku perpustakaan dalam proses peminjaman dan pengembalian buku perpustakaan.

\section{KESIMPULAN}

Kegiatan pengabdian kepada masyarakat ini bertujuan membantu menyelesaikan permasalahan pihak sekolah Uluwwul Himmah tentang bagaimana mengelola buku perpustakaan secara digitalisasi pada proses peminjaman dan pengembalian buku. Untuk menghasilkan aplikasi digitalisasi dapat dilakukan melalui 3 fase, yaitu pra kegiatan, pelaksanaan kegiatan dan pasca kegiatan. Bentuk luaran yang dihasilkan dari kegiatan pengabdian masyarakat ini adalah dalam bentuk Aplikasi berbasis desktop yaitu Digitalisasi Data Perpustakaan Dalam Proses Peminjaman dan Pengembalian Buku pada Perpustakaan Sekolah Islam 'Uluwwul Himmah

\section{SARAN}

Pelaksanaan pengabdian kepada masyarakat dalam bentuk pembuatan aplikasi berbasis dekstop dirasa dapat lebih bermanfaat bagi mitra (Sekolah Uluwwul Himmah) terkait dalam pengelolaan buku perpustakaan baik proses peminjaman dan pengembalian agar lebih efisien.

\section{DAFTAR PUSTAKA}

Febrian, J. (2017). Kamus Komputer dan Teknologi Informasi. Penerbit Informatika, Bandung.

Kahn, R. E., \& Cerf, V. G. (1988). The Digital Library Project Volume I: The World of Knowbots, (DRAFT): An Open Architecture For a Digital Library System and a Plan For Its Development. Reston, VA: Corporation for National Research Initiatives.

Suban, A. L., \& Reja, I. D. (2018, August). DIGITALISASI DATA PERPUSTAKAAN SEKOLAH DASAR INPRES NANGAMETING MAUMERE SEBAGAI PERWUJUDAN PAPERLESS OFFICE. In Prosiding SENTRA (Seminar Teknologi dan Rekayasa) (No. 1).

Atmoko, P. W., \& Si, M. (2015). Digitalisasi dan Alih Media. Malang: Universitas Bramelati. 